\title{
Interregional Inequality of Population Incomes: Problems of Methodology and Estimation in the Russian Federation
}

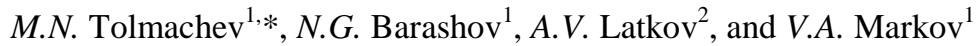 \\ *Corresponding author: tolmachev-mike@yandex.ru \\ ${ }^{1}$ Saratov Social-Economic Institute of the Plekhanov Russian University of Economics, \\ Saratov, Russia \\ ${ }^{2}$ Povolzhsky Institute of Management named after P.A. Stolypin, the branch of Russian Academy of National Economy and Public \\ Administration, Saratov, Russia
}

\begin{abstract}
Currently, the priority of the Russian Federation socio-economic development is to achieve sustainable economic growth. A significant obstacle to the achievement of this goal is the unevenness and disproportionality in the socio-economic development of the Russian regions. This circumstance makes the problem of an objective and adequate assessment of Russian regions the interregional differentiation particularly relevant. The study notes that the nominal monetary income of the population does not take into account regional differences in price level. This work discusses methodological approaches of reliable determination, advantages of weighted and unweighted estimates in the interregional inequality, special attention is paid to weighing the average per capita indicators of the subject of the Russia for the proportion of the region's population in the country's population. To assess the purchasing power of the population at the regional level, the authors propose to use a modified cost of living index. As a result of the study, the dynamics of the variation coefficient of the average per capita monetary incomes of the population and adjusted for the modified cost-of-living index were determined, on the basis of which the regions of Russia were divided into three groups. The efficiency of the transition to the analysis of incomes comparable in purchasing power, as comparison of weighted and unweighted variation coefficients, has been proved. The trend towards smoothing interregional inequality, which is caused by the accelerated growth of real incomes of the population in the low-income group of Russian regions.
\end{abstract}

Keywords: income differentiation, interregional inequality, weighted and unweighted estimates, regional imbalances, sigma-convergence.

\section{Introduction}

The question of the proportionality of national and regional economic systems development is traditionally one of the most important in terms of ensuring the economic growth sustainability and socio-economic development. The problem of disproportionality of economic development in regions has acquired particular urgency in Russia, as well as in a number of other states that have undergone a transition from a command-administrative economic system management to a market economy, as well as in many third world countries. In this connection, the problems of adequate assessment of Russian regions differentiation have particular importance. Many researchers are involved in this problem; systematic scientific and analytical work in this area is carried out at the Institute of Economics of the Russian Academy of Sciences and at the Institute of Economic Forecasting of the Russian Academy of Sciences.

To carry out an objective assessment of interregional differentiation dynamics, the following economic indicators are usually analyzed: 1) indicators characterizing the efficiency of the regional economy and the potential for its further development (gross regional product per capita; investment in fixed capital per capita) $[1,2]$; 2) indicators related to the social characteristics of the regions (average monthly nominal accrued wages of employees of organizations; average per capita cash income of the population). One can agree with the opinion that the last two of the listed indicators should be considered in two ways: on the one hand, as indicators of the social conditions of the formation of trajectories and strategies of the behavior of economic agents; on the other hand, as target social guidelines for the implementation of models of economic behavior of individuals and households in the constituent entities of the Russian Federation.

\section{Problem Statement}

In researching of interregional inequality, the problem of weighing per capita regional indicators by the proportion (number) of the region's population in the country's population is especially acute. Recently, this problem has been discussed in detail in a number of publications [3-5]. Both approaches have their advantages and disadvantages.

When using unweighted estimates, inequality is determined between regions. Weighted estimates, according to K.P. Gluschenko, characterize not interregional inequality, but inequality of the country's population, and distorted, gross, because they do not take into account intraregional inequality. As the author notes, when assessing inter-regional inequality, the "average" residents of the regions are compared to each other, and they are all equal, regardless of the region's population [6]. Therefore, when calculating inequality indicators, the average per capita incomes of the regions 
are compared not with the average income in Russia, but with a conditional value - the average simple arithmetic average of per capita incomes of all the regions.

In the work of M.Yu. Malkina argues in favor of a weighted approach, and notes that unlike the unweighted, a weighted approach evaluates not inequality, but unevenness, that is, the discrepancy between one structure of one distribution structure (income) and another structure (population). M.Yu. Malkina characterizes weighted scores as a contribution of interregional inequality to interpersonal inequality. The balanced approach is useful when it is necessary not only to state the problem, but to estimate its scale [7]. In favor of a balanced approach, the fact that in the study of certain phenomena, unweighted estimates are more susceptible to the influence of small regions, which distorts the scale of the phenomenon in these regions, is in favor [8].

\section{Research Questions}

What approaches exist to assess interregional income differentiation of the population?

What problems arise in the study of inter-regional inequality?

What are the advantages and disadvantages of weighted and unweighted estimates in the study of inter-regional inequality?

What is the best indicator for inter-regional comparisons of the purchasing power of the population?

\section{Purpose of the Study}

The article is devoted to comparative analysis methodological aspects of average per capita monetary incomes of the population in the Russian regions. The authors discuss approaches of reliable determination, advantages of different estimates in the interregional inequality. To assess the purchasing power of the population at the regional level, they use a modified cost of living index.

\section{Research Methods}

Modern statistics has an extensive methods for analyzing the parameters of irregularity both in statics and in dynamics. In the first case, there are indicators of differentiation, concentration, polarization, localization, accumulation, etc., in the broadest sense, which are special cases of measures of entropy (inequality). In the second the methods and indicators of convergence and divergence analysis [9].

The coefficient of variation, Gini index, Theil index, the Atkinson index, etc. are most often used to determine the level of inequality. These indicators are well known, reviewed in many papers [7, 10-12] and therefore the formulas for calculating them not shown here.

\section{Findings}

The results are based on data from the Federal State Statistics Service of the Russian Federation (Federal State Statistics Service of the Russian Federation (Rosstat)). The study involved 83 regions of the Russian Federation (except the Republic of Crimea and the city of Sevastopol, from 2005-2009, without the Chechen Republic due to the lack of data). The results obtained in $[8,13]$ show that 2005 is the year of the change in the trend of strengthening interregional inequality by its decline, and therefore the empirical analysis is carried out for 2005-2017.

The form of regions distribution in Russian Federation according to the level of per capita monetary incomes (including regions that are adjusted for purchasing power) allows judging the principal approximation of the actual distribution to a logarithmically normal.

The difference in the form of distribution from the normal is a necessary condition for the existence of inequality. Distribution of regions by average per capita income for the years 2005-2017 is unimodal, which should indicate the presence of convergence [14]. Analyzing convergence we follow the Bayer's and Fisher's works [15, 16].

The ratio of regional indicators to the all-Russian level indicates that the variability of the subsistence minimum is higher than the cost of a fixed set - the range of variation is 125.2 percent points against 84.3 in 2017 year.

Curious is the fact that the ratio of the cost of a fixed set of consumer goods and services with the size of the subsistence minimum as a whole decreases (Table 1) due to the rapid growth of the subsistence minimum.

Table 1. The ratio between the cost of consumer goods and services fixed set and the subsistence minimum, $\%$

\begin{tabular}{|l|c|c|c|c|c|c|c|c|c|c|}
\hline Indicator & $\mathbf{2 0 0 5}$ & $\mathbf{2 0 0 9}$ & $\mathbf{2 0 1 0}$ & $\mathbf{2 0 1 1}$ & $\mathbf{2 0 1 2}$ & $\mathbf{2 0 1 3}$ & $\mathbf{2 0 1 4}$ & $\mathbf{2 0 1 5}$ & $\mathbf{2 0 1 6}$ & $\mathbf{2 0 1 7}$ \\
\hline Russia & 150.5 & 147.1 & 146.3 & 144.2 & 146.2 & 142.6 & 142.3 & 134.3 & 141.3 & 145.4 \\
\hline Minimum & 131.9 & 119.7 & 120.5 & 119.6 & 118.9 & 103.8 & 100.9 & 98.4 & 98.7 & 95.3 \\
\hline Maximum & 180.0 & 184.0 & 182.9 & 186.0 & 181.6 & 184.4 & 177.0 & 160.7 & 161.0 & 164.6 \\
\hline
\end{tabular}

Source: compiled by the authors. 
Its value in 2017 increased by 3.34 times compared with 2005, with a rise in the cost of a fixed set by 3.23 times. Moreover, the largest difference in the dynamics of these indicators was observed in 2015. At the same time, there is a decrease in the variation of both the subsistence minimum (from 30.5 to $25.2 \%$ ) and the cost of a fixed set (from 23.5 to $16.3 \%$ ) throughout the study period, which indicates the trend of leveling prices in Russian Federation regions.

The data in Table 1 shows that the minimum and maximum ratio between the cost of consumer goods and services fixed set and the size of the subsistence minimum of the regions also decreased, and the minimum value is falling at the fastest rate. The strongest decline is observed in the Nenets Autonomous District, Tyumen Region, Altai Territory, Kabardino-Balkarian Republic and the Republic of North Ossetia - by 33.2-47.6 percent item. The smallest - in the Yaroslavl, Omsk, Vladimir regions. In two regions, the ratio of the cost of a fixed set to the subsistence minimum increased: in the Republic of Altai by 13.4 percent point, and in St. Petersburg - 1.1 percent item. The Nenets Autonomous District is the only region in which the cost of a fixed set is lower than the subsistence minimum - by $4.7 \%$.

Based on the current trends in regional indicators, we propose a modified cost-of-living index for inter-regional comparisons of the purchasing power of the population, calculated as the geometric average of the ratios between the cost of consumer goods and services fixed set and the subsistence minimum in the region with the same indicator at the national level.

Figure 1 shows the dynamics of the variation coefficient of the average per capita and the average per capita monetary incomes of the population adjusted for the modified cost of living index.

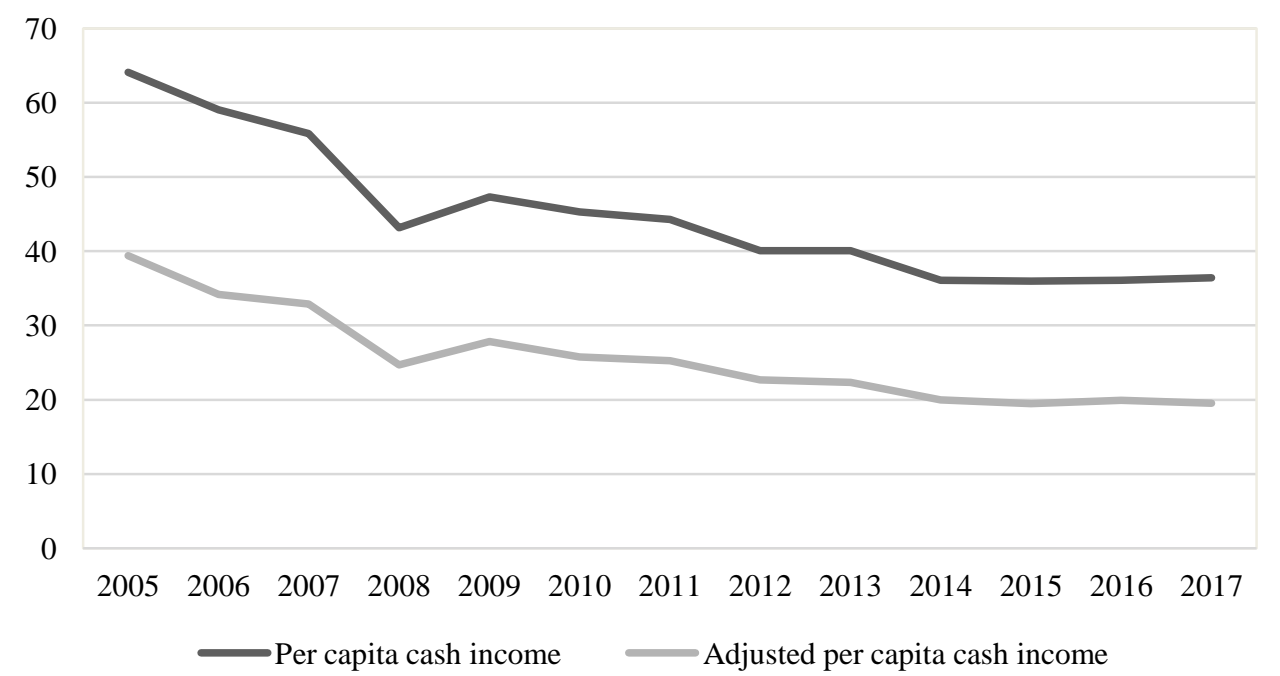

Figure 1. The variation coefficient of average per capita cash income of the population in Russian regions 2005-2017 Source: compiled by authors.

The transition to comparable incomes leads to the fact that the average per capita cash income, calculated using the weighted average arithmetic formula, where the weights are the shares of the regional population, differ from the per capita cash income in the Russian Federation as a whole (Table 2). The discrepancies are 3.4-5.2\% and are related to the Rosstat method of calculating average prices. When calculating average prices for certain types of goods representative for the Russian regions, the weights are the proportion of the population of the surveyed cities in the region, and for the Russia as a whole - the share of consumption of goods of the representative of the Russian regions in its total consumption in country.

Table 2. Discrepancies between average per capita monetary and comparable monetary incomes of the Russian population

\begin{tabular}{|c|c|c|c|}
\hline Year & $\begin{array}{c}\text { Per capita cash income, } \\
\text { rubles }\end{array}$ & $\begin{array}{c}\text { Per capita comparable cash } \\
\text { income, rubles }\end{array}$ & Discrepancies, \% \\
\hline 2005 & 8088.3 & 7809.7 & 3.4 \\
\hline 2006 & 10154.8 & 9683.8 & 4.6 \\
\hline 2007 & 12540.2 & 11882.2 & 5.2 \\
\hline 2008 & 14863.6 & 14329.3 & 3.6 \\
\hline 2009 & 16895.0 & 16172.8 & 4.3 \\
\hline 2010 & 18958.4 & 18243.3 & 3.8 \\
\hline 2011 & 20780.0 & 20052.6 & 3.5 \\
\hline 2012 & 23221.1 & 22431.0 & 3.4 \\
\hline 2013 & 25928.2 & 25056.9 & 3.4 \\
\hline 2014 & 27794.2 & 26700.8 & 3.9 \\
\hline 2015 & 30746.5 & 29518.5 & 4.0 \\
\hline 2016 & 30698.3 & 29159.8 & 5.0 \\
\hline 2017 & 31318.1 & 29771.6 & 4.9 \\
\hline
\end{tabular}

Source: compiled by authors. 
Figure 2 shows the dynamics of the variation coefficient of the adjusted average.

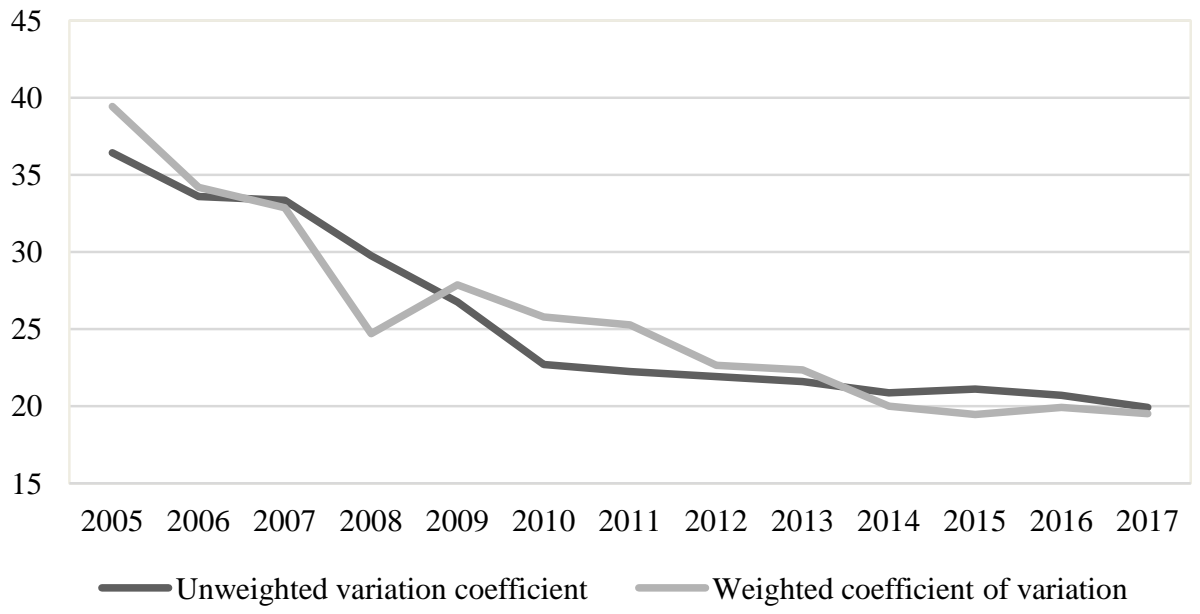

Figure 2. The coefficient of variation of the adjusted per capita cash income of the population in Russian regions for 2005-2017 Source: compiled by authors.

The dynamics of both weighted and unweighted coefficients of variation are similar. There is a steady downward trend in variations in the average per capita income of the population, which confirms the presence of sigmaconvergence in the Russian regions.

Table 3 presents the grouping of Russian regions according to the level of the adjusted per capita monetary income of the population. The regions are grouped into three groups: the first group includes 22 regions with the highest incomes, the second - 27 regions with average incomes, and the third group - 34 regions (33 regions for 2005-2010 due to the lack of data for the Chechen Republic) with the lowest incomes. The choice of the number (non-composition) of the regions in each group was determined according to 2005 data so that the proportion of the population in the groups was approximately the same. The small unevenness of the second and third groups is explained by the fact that the last region, which is included in the second group, was the Moscow region with a population of 6,760.3 thousand people.

Table 3. Grouping of Russian regions according to the level of adjusted per capita monetary income of the population

\begin{tabular}{|c|c|c|c|c|c|c|c|c|c|c|c|}
\hline Group & $\mathbf{2 0 0 5}$ & $\mathbf{2 0 0 9}$ & $\mathbf{2 0 1 0}$ & $\mathbf{2 0 1 1}$ & $\mathbf{2 0 1 2}$ & $\mathbf{2 0 1 3}$ & $\mathbf{2 0 1 4}$ & $\mathbf{2 0 1 5}$ & $\mathbf{2 0 1 6}$ & $\mathbf{2 0 1 7}$ \\
\hline \multicolumn{1}{|c|}{ Real disposable income of the population,\% of the previous year } \\
\hline 1 & 112.9 & 103.5 & 105.0 & 100.2 & 104.7 & 104.4 & 98.9 & 96.6 & 100.3 & 101.7 \\
\hline 2 & 112.7 & 101.8 & 106.7 & 100.9 & 106.1 & 103.3 & 101.8 & 97.5 & 95.7 & 102.0 \\
\hline 3 & 112.3 & 98.7 & 110.6 & 100.0 & 104.7 & 103.2 & 99.8 & 97.1 & 99.0 & 101.9 \\
\hline \multicolumn{1}{|c|}{ The proportion of the population in the total population\% } \\
\hline 1 & 33.4 & 43.3 & 41.8 & 41.4 & 40.2 & 42.8 & 43.9 & 44.2 & 42.1 & 42.3 \\
\hline 2 & 34.7 & 30.0 & 30.0 & 30.4 & 31.8 & 32.1 & 29.1 & 29.7 & 29.9 & 29.2 \\
\hline 3 & 31.9 & 26.7 & 28.2 & 28.2 & 28.0 & 25.1 & 27.0 & 26.1 & 28.0 & 28.5 \\
\hline
\end{tabular}

Source: compiled by authors.

The change in per capita incomes changes the composition of the regions in groups and the proportion of the population in the first group of regions increases, replacing the group with average and low per capita incomes. This is increasing the concentration of the population in rich regions. The weighted coefficient of variation becomes less unweighted.

\section{Conclusion}

Thus, based on the study, we can draw conclusions:

1) the transition to the analysis of incomes comparable in purchasing power turns out to be justified - there is a significant decrease in variation (by 38.5-46.5\%) in the level of average per capita incomes of the population, also for the period under review, there is a clear tendency to reduce the variation of the average per capita incomes of the population, i.e. sigma convergence;

2) the results obtained are consistent with the point of view expressed in the work of M.Yu. Malkina [13] regarding the values of the weighted and unweighted coefficient of variation with a change in the proportion of the population in groups; This fact makes it possible not to abstract from one of the approaches to calculating the variation indicators, but allows one to compare the weighted and unweighted variation coefficients in order to determine the polarization of the population in low or high income groups. 
In conclusion, it should be noted that the decrease in interregional inequality in the Russian Federation was due primarily to the accelerated growth of real incomes of the population in the low-income group of regions. This is especially evident in the period 2008-2009, when a sharp decrease in the weighted coefficient of variation in 2008 is explained by a higher growth in real incomes of the population in the third group of regions compared to the first, and the increase in the coefficient of variation in 2009 is, on the contrary, an increase real income in a high-income group of regions.

Based on the calculation of Theil indexes (Theil index itself and the average logarithmic deviation), the authors found that the trend of these indicators is similar to the coefficient of variation.

Attention is drawn to the fact that if before 2012 the values of the Theil index were slightly higher than the average logarithmic deviation, and this indicates a greater contribution to the inequality of high-income regions, then, starting from 2012, the values of the two Theil indexes almost coincide. This circumstance confirms the obtained conclusion about the equalization of inequality, mainly due to the accelerated growth of incomes of the population in "poor" regions.

\section{References}

1. S. Anand, S.M.R. Kanbur, The Kuznets process and the inequality-development relationship. Journal of Development Economics, (1), 25-52. DOI: 10.1016/0304-3878(93)90103-T(1993).

2. M. Friedman, The role of monetary policy. The American Economic Review, 58(1), 1-17. DOI: 10.1007/978-1-34924002-9_11 (1968).

3. F. Bouvet, EMU and the dynamics of regional per capita income inequality in Europe. The Journal of Economic Inequality, 8(3), 323-344. DOI: 10.1007/s10888-010-9129-0 (2010).

4. N.W. Ismail, Growth and convergence in ASEAN: A dynamic panel approach, International Journal of Economics and Management, 2(1), 127-140. URL: https://www.researchgate.net/publication/277742339 (2008).

5. D. Mookherjee, A.F. Shorrocks, A decomposition analysis of the trend in UK income inequality. Economic Journal, 92(368), 886-902. DOI: 10.2307/2232673 (1982).

6. K.P. Gluschenko, On estimation of inter-regional inequality. Spatial Economics, 4, 39-58. DOI: 10.14530/se.2015.4.039-058 (2015). [in Rus.].

7. M.Yu. Malkina, On the issue of weighting in interregional studies. Spatial Economics, 1, 163-184. DOI: 10.14530/se.2016.1.163-184058 (2016). [in Rus.].

8. M.N. Tolmachev, Theoretical and empirical approaches to convergence of agricultural production. Science Journal of Volgograd State University. Global Economic System, 1(20), 193-199 (2012). [in Rus.].

9. V.A. Markov, Spatial heterogeneity in the development of regional labor markets: statistical methods and models. Saratov, Russia: SSEI of Plekhanov Russian University of Economics (2015). [in Rus.].

10. P. Allanson, Income stratification and between-group inequality. Economics Letters, 124(2), 227-230. DOI: 10.1016/j.econlet.2014.05.025 (2014).

11. C.R. Azzoni, Economic growth and regional income inequality in Brazil, The Annals of Regional Science, 35(1), 133-152. DOI: 10.1007/s001680000038 (2001).

12. R. Lerman, S. Yitzhaki, Income inequality effects by income source: A new approach and applications to the United States. The Review of Economics and Statistics, 67(1), 151-156. DOI: 10.2307/1928447 (1985).

13. O.S. Balash, Convergence spatial analysis of Russia's regions, Izv. Saratov Univ. (N.S.), Ser. Economics. Management. Law, 4(12), 45-52 (2012). [in Rus.].

14. A.V. Brovkova, Improving methods of statistical analysis of socio-economic inequality and regional convergence in Russia. Vestnik Saratov State Socio-Economic University, 2(51), 113-117 (2014). [in Rus.].

15. C. Bayer, F.Juessen, Convergence in West German regional unemployment rates, German Economic Review, 8(4), 510-535. DOI: 10.1111/j.1468-0475.2007.00416.x (2007).

16. M. Fischer, C. Stirböck, Pan-European regional income growth and club-convergence insights from a spatial econometric perspective. Annals of Regional Science, 40(4), 693-721. DOI: 10.1007/s00168-005-0042-6 (2006). 